\title{
LA EXTENSIÓN AL DERECHO ADMINISTRATIVO SANCIONADOR DEL DERECHO HUMANO A SER INDEMNIZADO POR CONDENAS PENALES FIRMES ANULADAS*
}

\author{
The extent to sanctioning administrative law of the human \\ right to be compensated because of firm conviction reversed
}

\author{
Manuel Rodríguez Portugués \\ Universidad de Córdoba (España) \\ dp2ropom@uco.es
}

http://dx.doi.org/10.18543/ed-66(2)-2018pp191-217

Recibido: 30.10 .2018

Aceptado: 21.11.2018

\section{Resumen}

El artículo 3 del Protocolo número 7 del Convenio Europeo de Derechos Humanos reconoce un derecho indemnizatorio al afectado por una condena penal firme

* Cómo citar / Citation 'Chicago-Deusto' (Autor-fecha / Author-date / Lista de referencias / Reference list entries): Rodríguez Portugués, Manuel. 2018. «La extensión al derecho administrativo sancionador del derecho humano a ser indemnizado por condenas penales firmes anuladas». Estudios de Deusto 66, n. ${ }^{\circ}$ 2: 191-217. http://dx.doi.org/10.18543/ed66(2)-2018pp191-217.

Proyecto de Investigación DER2015-67695-C2-2-P (MINECO-FEDER). Grupo de Investigación SEJ-196. El presente trabajo tiene su origen en una ponencia presentada en el Congreso «Justicia, Administración Pública y Derechos Fundamentales», celebrado en la Facultad de Derecho de la Universidad de Córdoba durante los días 16 y 17 de noviembre de 2017. Agradezco las sugerencias y observaciones que se le realizaron a la misma, especialmente por parte de la Profesora Alarcón Sotomayor, el Profesor Cubillo LóPez y el Profesor LóPEZ BENÍTEZ. Sus objeciones han servido para enriquecer el texto que ahora se publica, de cuyos errores o desaciertos me hago, por supuesto, exclusivamente responsable. 
posteriormente anulada por motivos ajenos al condenado. El presente trabajo explora la posibilidad de que este derecho sea ejercitable también en el ámbito administrativo sancionador, en concreto, en relación con la anulación de sanciones administrativas firmes, así como las consecuencias que ello tendría para el sistema español de responsabilidad patrimonial de la Administración pública.

\section{Palabras clave}

Sanciones administrativas; responsabilidad patrimonial de la Administración pública; Convenio Europeo de Derechos Humanos.

\section{Abstract}

Article 3 of Protocol No. 7 of the European Convention on Human Rights recognizes a right to compensation to the person affected by a firm criminal conviction later annulled for reasons unrelated to the convict. The present work explores the possibility that this right is also exercisable in the sanctioning administrative sphere, in particular, in relation to the annulment of firm administrative sanctions, as well as the consequences that this would have for the Spanish system of patrimonial responsibility of the Public Administration.

\section{Keywords}

Administrative sanctions; patrimonial responsibility of the Public Administration; European Convention on Human Rights. 


\begin{abstract}
SUMARIO: I. INTRODUCCIÓN. II. APLICACIÓN DEL ARTÍCULO 3 DEL PROTOCOLO NÚM. 7 CEDH EN EL ÁMBITO SANCIONADOR ADMINISTRATIVO. III. PRESUPUESTO DE HECHO. 1. Resolución sancionadora firme. 2. Anulación posterior por hechos nuevos o nuevas revelaciones que demuestren que ha habido error, y siempre y cuando dicho desconocimiento no se hubiera debido en todo o en parte a la persona afectada. 2.1. Una importante modulación del régimen de responsabilidad patrimonial por acto administrativo ilegal. 2.2. La revisión y revocación de sanciones administrativas firmes en derecho español. IV. TITULARIDAD Y OBJETO DEL DERECHO. 1. Personas fisicas y también personas morales o jurídicas. 2. La indemnización objeto del derecho. 2.1. De daños patrimoniales y no patrimoniales. 2.2. De daños morales y de la «pérdida de oportunidad». V. PRocedIMIENTO. 1. La vía administrativa: revisión de oficio o reclamación de responsabilidad patrimonial de la Administración. 2. El derecho del artículo 3 del protocolo 7, ¿derecho fundamental a efectos constitucionales internos? VI. CONCLUSIÓN. BIBLIOGRAFÍA.
\end{abstract}

\title{
I. INTRODUCCIÓN
}

Entre los derechos reconocidos en el CEDH hay dos que han tenido particular influencia para las Administraciones Públicas y para una gran parte de los actos que esta dicta cada día, las sanciones administrativas. Se trata de los derechos reconocidos en los artículos 6 y $7 \mathrm{CEDH}$, los denominados derechos a un juicio equitativo y a la legalidad penal. Como es sabido, pese a que expresamente estos preceptos se refieren sólo a la materia «penal», desde muy pronto el TEDH entendió que esos derechos también se reconocen en el Convenio, con ciertas adaptaciones y modulaciones, frente a la potestad sancionadora de las Administraciones públicas nacionales.

Con el tiempo, además, los Estados firmantes han ido incorporando otros derechos al catálogo de 1950, mediante la adopción de Protocolos adicionales. Uno de ellos ha afectado también particularmente al poder punitivo de los Estados: el Protocolo núm. 7. De entre los derechos reconocidos en este Protocolo, ya han recibido abundante atención doctrinal y jurisprudencial la doble instancia judicial en materia penal, contenida en el artículo 2, y la prohibición «non bis in ídem», contemplada en el artículo 4.

Sin embargo, apenas se ha reparado en el derecho reconocido en el artículo 3 y en las repercusiones que dicho derecho puede tener en materia sancionadora administrativa. Se trata del derecho a obtener una indemnización por parte de quien ha sufrido una pena en virtud de una sentencia penal condenatoria firme cuando esta resulte posteriormente anulada o revocada porque un hecho nuevo o nuevas revelaciones demuestren que hubo error judicial: 
«Cuando una sentencia penal condenatoria firme resulte posteriormente anulada o se conceda una medida de gracia porque un hecho nuevo o nuevas revelaciones demuestren que ha habido error judicial, la persona que haya sufrido la pena en virtud de esa condena será indemnizada conforme a la ley o al uso vigente en el Estado respectivo, excepto cuando se pruebe que la no revelación en tiempo oportuno del hecho desconocido fuere imputable total o parcialmente a dicha persona».

Hay muy pocos pronunciamientos del TEDH sobre este derecho; y ninguno directamente sobre su aplicabilidad al ámbito sancionador administrativo. Menos aún existen pronunciamientos al respecto de nuestros órganos judiciales nacionales. En general, da la impresión de que los actores jurídicos apenas se han percatado de la existencia de este precepto. Y, sin embargo, su reconocimiento plantea a nuestros efectos -es decir, el de su posible proyección a la Administración pública- múltiples cuestiones de las que pueden derivarse consecuencias determinantes. ¿Es aplicable también, como los derechos de los artículos 6 y 7 del Convenio, al erróneo ejercicio de la potestad sancionadora de la Administración? Y si lo es, ¿en qué medida? ¿Cuáles son sus requisitos? ¿A qué alcanza la indemnización correspondiente? ¿Quién puede pedirla? ¿Mediante qué procedimientos se puede hacer valer? $\mathrm{Y}$, además, en relación con esta última cuestión: ¿se trata, a los efectos de nuestro ordenamiento constitucional, de un derecho fundamental integrado o reconducible, vía interpretación, a alguno de los reconocidos por nuestra Constitución? ¿O se trata, sin más, de un derecho de «legalidad ordinaria», es decir, de un derecho derivado de las obligaciones internacionales contraídas por España?

\section{APLICACIÓN DEL ARTÍCULO 3 DEL PROTOCOLO NÚM. 7 CEDH EN EL ÁMBITO SANCIONADOR ADMINISTRATIVO}

Lo primero que plantea a tales efectos este derecho es si existe no sólo en relación con las penas en sentido estricto, sino también en relación con las sanciones administrativas. Una lectura literal del precepto llevaría inmediatamente a una respuesta negativa: está bien a las claras que el artículo 3 del Protocolo 7 se refiere sólo a la materia penal, pues no en vano habla únicamente de sentencia «penal»y de error «judicial» ${ }^{1}$.

${ }^{1}$ En este sentido, encuentra discutible la extensión del precepto al ámbito de las sanciones administrativas Unai ABERASTURI GORRIÑO, «Comentario al artículo 3 del Protocolo número 7», en Convenio Europeo de Derechos Humanos. Comentario sistemático, $2^{\mathrm{a}}$ ed., dir. Iñaki Lasagabaster Herrarte, Civitas, Cizur Menor (Navarra), 2009, p. 901, afirmando que las sanciones administrativas «difícilmente pueden ser firmes» y tener los efectos de «cosa juzgada», y que, de tenerlos, sería por inactividad impugnatoria del 
Pero se trataría, sin duda, de una conclusión apresurada. También los artículos 6 y 7 CEDH hablan exclusivamente de «tribunal», «litigio», «acusación en materia penal», «sentencia», «sala de audiencia», «pena», «delito»..., nociones todas ellas propias del ámbito judicial y del Derecho penal. Y, sin embargo, ello no ha sido obstáculo para que, casi desde los primeros momentos de rodaje del CEDH, el TEDH haya dejado claro que esos derechos se pueden esgrimir también, con las modulaciones y adaptaciones oportunas, en el ámbito administrativo sancionador ${ }^{2}$. La razón de ello radica en que, para el TEDH, el Convenio maneja una noción de «materia penal» autónoma de los derechos nacionales, y ello por exigencias de la eficacia del propio Convenio. En efecto, si a los legisladores nacionales les bastara con atribuir la represión de los ilícitos a la Administración, en vez de a los tribunales, para escapar del ámbito de aplicación de los artículos 6 y $7 \mathrm{CEDH}$, los derechos reconocidos en los mismos quedarían convertidos en papel mojado.

La interpretación del TEDH ha sido siempre, por tanto, tajantemente favorable a entender incluidas en los artículos 6 y 7 CEDH también las infracciones y sanciones administrativas. Pero no se trata de una aplicación general y automática. La medida aflictiva en cuestión debe responder a la noción autónoma de «pena» propia del Convenio. Y ello se producirá, en concreto, cuando dicha medida supere positivamente la aplicación de una serie de criterios utilizados usualmente a estos efectos por el TEDH y conocidos como «criterios Engel» por el asunto en el que fueron enunciados por primera vez ${ }^{3}$. Dichos criterios son los siguientes:

- la calificación normativa por el derecho nacional de la infracción enjuiciada, es decir, si es considerada, según la técnica jurídica del Estado demandado, como Derecho penal o Derecho administrativo sancionador;

- la naturaleza misma de la infracción, es decir, qué tipo de orden jurídico (penal, disciplinario, administrativo...) es transgredido por la omisión o la acción sancionada;

- y el grado de severidad de la sanción que puede sufrir el interesado. Por ejemplo, en «una sociedad sujeta a la preeminencia del derecho, son de «materia penal» las privaciones de libertad susceptibles de

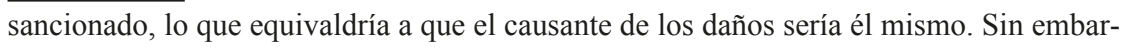
go, dichas afirmaciones carecen de fundamento, como se desprende de lo que se expone en el texto a continuación.

${ }^{2}$ Un recorrido por esa jurisprudencia puede verse en Silvia BERTAZZO, «El Derecho Administrativo Sancionador a la luz del Convenio Europeo de Derechos Humanos», en Revista General de Derecho Administrativo núm. 39 (2015).

3 Vid. STEDH de 8 de junio de 1976, Engel y otros c. Holanda. 
ser impuestas a título represivo, excepto aquellas que por su naturaleza, su duración o sus modalidades de ejecución no son susceptibles de causar un perjuicio importante. Así lo requiere la gravedad de la cuestión, las tradiciones de los Estados contratantes y el valor que el Convenio atribuye al respeto de la libertad física de la persona» ${ }^{4}$.

La infracción merecerá ser calificada de «penal», aunque para el Derecho nacional sea «administrativa», cuando responda a algunos de estos tres criterios, sin que deban necesariamente darse los tres conjuntamente y sin que exista entre ellos ninguna relación de preferencia. De su jurisprudencia parece deducirse que el TEDH maneja en realidad una noción unitaria de «pena» $\mathrm{o}$ «sanción», con independencia del poder del Estado que la imponga ${ }^{5}$, y cuyo núcleo definidor reside en la idea de $\left\langle\right.$ castigo» ${ }^{6}$.

Estas consideraciones deben completarse, no obstante, con una importante matización en relación con determinadas sanciones disciplinarias. Cuando este tipo de sanciones se aplica a funcionarios que son partícipes del poder público, el TEDH realiza una interpretación restrictiva dejando este tipo de medidas fuera de la noción «materia penal» a los efectos del Convenio. Ejemplo de esta interpretación, inspirada en lo que para nosotros sería un

${ }^{4}$ Apartado 82 de la referida Sentencia Engel.

5 Es más: la ha aplicado, incluso, frente al poder legislativo en un caso en el que la Cámara de Diputados de Malta, ejerciendo funciones materialmente ejecutivas o judiciales, impuso unas sanciones a un ciudadano sin respetar las garantías del Convenio. Vid. STEDH de 27 de agosto de 1991, Demicoli c. Malta.

${ }^{6}$ STEDH de 4 de noviembre de 2008, Balsyté-Lideikiene c. Lituania: «58. En cuanto a la naturaleza de la sanción, el Tribunal atribuye un significado especial al artículo 20 del Código de Delitos Administrativos, que estipula que el objeto de la sanción administrativa es castigar a los delincuentes y disuadirles de delinquir de nuevo. El Tribunal recuerda que un carácter punitivo es el rasgo típico y habitual de una sanción penal (ver la anteriormente mencionada Sentencia Öztürk, ap. 53). (...) 61. En resumen, el carácter general de la disposición legal infringida por la demandante junto con el propósito disuasorio y punitivo de la sanción, así como la severidad de la sanción que podría recaer sobre la demandante, bastan para demostrar que el delito en cuestión era, en términos del artículo 6 del Convenio, de naturaleza penal. Por consiguiente, el Tribunal considera que el artículo 6.3 d) es aplicable en el caso que nos ocupa» (el énfasis es nuestro). STEDH de 29 de septiembre de 2011, Flisar contra Eslovenia: «26. Volviendo al presente caso, el Tribunal observa que las disposiciones del MOA se aplican a toda la población y no a un grupo que posee un estatus especial. Además, aunque tratándose de «delitos de reglamentación», el MOA se refiere a las disposiciones del Código Penal a fin de ser utilizadas por analogía (véase el apartado 14). Por último, se le impuso una multa de 625 euros, lo que se prescribe como un castigo (véase el apartado 17) y no como indemnización por el acto cometido» (el énfasis es añadido). 
tipo de «relaciones de sujeción especial» ${ }^{7}$, es la Decisión del TEDH de 22 de junio de 2000, Linde Falero c. España, en relación con la sanción disciplinaria de separación del servicio de un guardia civil ${ }^{8}$.

En cualquier caso, a la luz de los «criterios Engel», el TEDH ha considerado como «penales» las siguientes sanciones que para el Derecho nacional del Estado demandado en cuestión eran administrativas:

\section{- la imposición de diversas sanciones disciplinarias en el ámbito peni- tenciario";}

${ }^{7}$ Las relaciones especiales de sujeción pueden definirse como «las relaciones jurídicoadministrativas caracterizadas por una duradera y efectiva inserción del administrado en la esfera organizativa de la Administración, a resultas de la cual queda sometido a un régimen jurídico peculiar que se traduce en un especial tratamiento de la libertad y de los derechos fundamentales, así como de sus instituciones de garantía, de forma adecuada a los fines típicos de cada relación» (Mariano LóPEZ BENÍTEZ, Naturaleza y presupuestos constitucionales de las relaciones especiales de sujeción, Civitas, Madrid, 1994, pp. 161 y 162). Esta definición ha sido literalmente seguida por los tribunales: véase el FJ $5^{\circ}$ de la STSJ de Madrid (Sala de lo Contencioso-Administrativo, Sección $8^{\mathrm{a}}$ ) n ${ }^{\mathrm{o}}$ 714/2013, de 9 de octubre: «Debe tener presente el ahora recurrente, que no es un mero administrado sino que se halla respecto de la Administración en la que se inserta (en este caso el Colegio Notarial) en una situación de relación de especial sujeción, que son un tipo de relaciones jurídico-administrativas caracterizadas por una duradera y efectiva inserción del administrado en la esfera organizativa de la Administración, a resultas de la cual queda sometido a un régimen jurídico peculiar que se refleja en un especial tratamiento de la libertad, derechos y deberes del administrado de modo adecuado a los fines típicos de cada relación». El Tribunal, sin embargo, aplica incorrectamente la definición doctrinal utilizada porque las relaciones colegiado-colegio no reúnen las características señaladas. De hecho, el propio LóPEZ BENíTEZ, en la obra citada, dedica expresamente unas cuantas páginas a negar que tengan tal consideración las relaciones de las corporaciones profesionales con sus miembros (1994: 253-260).

8 Para ello, la Decisión se remite a la doctrina sentada en la STEDH de 8 de diciembre de 1999, Pellegrin c. Francia, en la que se señala: «66. En consecuencia, el Tribunal decide que únicamente se sustraerán del campo de aplicación del artículo 6.1 del Convenio, los litigios de los funcionarios cuyo empleo esté caracterizado por actividades específicas de la Administración Pública en la medida en la que ésta actúa como detentadora del poder público encargado de la protección de los intereses generales del Estado o de otras colectividades públicas. Un ejemplo claro de tales actividades lo constituirían las fuerzas armadas y la policía. En la práctica, el Tribunal examinará, en cada caso, si el puesto del demandante implica -teniendo en cuenta la naturaleza de las funciones y de las responsabilidades que supone- una participación directa o indirecta en el ejercicio del poder público y en las funciones tendentes a proteger los intereses generales del Estado o de otras colectividades públicas. Al hacerlo, el Tribunal tendrá en cuenta, a título indicativo, las categorías de actividades y los puestos de trabajo enumerados por la Comisión Europea en su comunicación del 18 de marzo de 1988 y por el Tribunal de Justicia de la Comunidad Europea (apartados 37 a 41 «supra»)».

9 Vid. STEDH de 28 de junio de 1984, Campbell y Fell c. Reino Unido. La gravedad de la sanción derivaba aquí de que las sanciones disciplinarias impuestas conllevaban 
- una multa en materia de tráfico ${ }^{10}$;

- la retirada de puntos del permiso de conducir ${ }^{11}$;

- una amonestación con confiscación de material impreso ${ }^{12}$;

- una multa de 625 euros $^{13}$;

- la revocación del carnet de conducir ${ }^{14}$.

No hay, por tanto, ningún problema en entender que la garantía indemnizatoria contenida en el artículo 3 del Protocolo 7 sea aplicable también en materia sancionadora administrativa ${ }^{15}$. Más bien al contrario: la noción autónoma de «materia penal» elaborada por la jurisprudencia del TEDH, junto a la finalidad de asegurar la eficacia del Convenio, imponen la extensión de dicha aplicación. No en vano los «criterios Engel» han sido utilizados asimismo en relación con los derechos reconocidos por otros artículos de este mismo Protocolo 7, como particularmente respecto a la garantía «non bis in ídem» contenida en su artículo $4^{16}$.

Ahora bien, la afirmación de que las sanciones administrativas están incluidas en el ámbito de protección de este derecho, no implica desconocer, sin embargo, que dicha inclusión deba entenderse realizada con ciertas adaptaciones y matizaciones. A dichas adaptaciones y matizaciones de los

pérdidas en la reducción de la pena de prisión, con lo cual equivalía a una pena de privación de libertad.

10 Vid. STEDH de 25 de agosto de 1987, Lutz c. Alemania.

11 Vid. STEDH de 23 de septiembre de 1998, Malige c. Francia. El razonamiento es reseñable: «39. En cuanto al grado de gravedad, el Tribunal señala que la retirada de puntos puede terminar en la pérdida de validez del permiso de conducir. Ahora bien, es indiscutible que el derecho a conducir un vehículo a motor es de gran utilidad para la vida corriente y el ejercicio de una actividad profesional. El Tribunal, al igual que la Comisión, deducen de ello que, aunque la medida de retirada presenta un carácter preventivo, reviste además un carácter punitivo y disuasivo y se parece por tanto a una pena accesoria».

12 Vid. STEDH de 4 de noviembre de 2008, Balsyté-Lideikiene c. Lituania, aunque en este caso la amonestación podía haber sido sustituida por una multa e incluso, según las peculiaridades propias del Derecho nacional en cuestión, por una detención administrativa de 30 días.

13 Vid. STEDH de 29 de septiembre de 2011, Flisar contra Eslovenia.

14 Vid. STEDH de 24 de enero de 2012, Toma c. Rumanía.

15 En esta línea, vid. Kees Flinterman, «Compensation for miscarriage of justice (Article 3 of Protocol No. 7), en Theory and Practice of the European Convention on Human Rights, Pieter van Dijk, Fried van Hoof, Arjen van Rijn y Leo Zwaak (ed.), $4^{\mathrm{a}}$ ed., 2006, p. 975; y Christoph GRABENwARTER, European Convention on Human Rights. Comentary, C. H. Beck - Hart - Nomos, Freiburg, 2014, p. 433.

${ }^{16}$ Pueden citarse a este respecto las SSTEDH de 6 de junio de 2002, Sailer c. Austria; de 30 de mayo de 2002, W. F. c. Austria; y de 10 de febrero de 2009, Sergey Zolotukhin c. Rusia. Particularmente importante es la de 31 de mayo de 2011, Kurdov e Ivanov c. Bulgaria, que usa expresamente los «criterios Engel» para interpretar el artículo 4 del Protocolo 7. 
derechos en materia penal reconocidos por el Convenio en relación con el ámbito sancionador administrativo se ha referido también en ocasiones el TEDH. El fundamento de tales adaptaciones a la esfera sancionadora administrativa, desde la penal, apunta a la propia naturaleza de las Administraciones públicas, no equiparables desde el punto de vista estructural e institucional a los órganos del poder judicial ${ }^{17}$.

Por ello, la aplicación del artículo 3 del Protocolo 7 al ámbito sancionador administrativo debe hacerse también con las adaptaciones y matizaciones requeridas por nuestro ordenamiento jurídico-administrativo sancionador y obliga a examinar cuidadosamente el alcance del derecho reconocido en dicho artículo por lo que a las sanciones administrativas se refiere, tanto desde el punto de vista de los requisitos exigibles para su ejercicio como de los sujetos que pueden ser titulares del derecho, el contenido del mismo y el procedimiento apropiado para hacerlo valer (lo que plantea, por ejemplo, la cuestión de los plazos para instarlo y desde cuándo se computa dicho plazo).

\section{PRESUPUESTO DE HECHO}

\section{Resolución sancionadora firme}

El primer requisito del que habla el artículo 3 es el de la existencia de una «sentencia penal condenatoria firme». En el ámbito administrativo sancionador, integran este supuesto tanto una resolución sancionadora firme por no haberse recurrido en plazo como una resolución sancionadora que deviene firme por haber recaído en relación con ella una sentencia contencioso-administrativa confirmatoria firme.

Este requisito de la resolución administrativa plantea, no obstante, alguna duda desde el punto de vista del ente autor de la misma: ¿es, a los efectos de este derecho, resolución sancionadora la dictada por entes que no tienen en sentido estricto la condición de Administración pública, como las corporaciones de derecho público? La respuesta ha de ser afirmativa en relación, al menos, con aquellas corporaciones de derecho público -como algunos colegios profesionales- cuya afiliación se impone como obligatoria para la realización de la actividad privada en cuestión. En tales casos, el ejercicio de la potestad disciplinaria es sustancialmente equiparable al ejercicio de un poder punitivo público, razón por la cual el artículo 2.4 de la Ley 39/2015, de 1 de octubre, de Procedimiento Administrativo Común (en adelante, LPAC), determina la aplicación supletoria de esta Ley al «ejercicio de las funciones públicas» atribuidas a estas entidades. Lo mismo hay que decir del ejercicio de potestades semejantes por parte de

${ }_{17}$ Así, por ejemplo, en cuanto al alcance de la garantía de la independencia e imparcialidad del tribunal (STEDH de 25 de agosto de 1987, Lutz c. Alemania). 
entes que no tienen formalmente la consideración de corporaciones de derecho público, pero que sí han sido destinatarias de la atribución de relevantes funciones públicas por parte del ordenamiento, tales como las desde antiguo conocidas en la doctrina española como «asociaciones de configuración legal» ( $v$. $g r$. federaciones y organizaciones deportivas profesionales) ${ }^{18}$. En todos estos casos, además, las sanciones pueden revestir una notable gravedad (normalmente la inhabilitación por períodos más o menos largos, y que pueden ser irreversibles para la biografia profesional de la persona afectada).

\section{Anulación posterior por hechos nuevos o nuevas revelaciones que demuestren que ha habido error, y siempre y cuando dicho desconocimiento no se hubiera debido en todo o en parte a la persona afectada}

El artículo 3 del Protocolo 7 exige también que la «sentencia penal condenatoria firme» sea posteriormente anulada, pero no por cualquier motivo, sino porque se demuestre que la decisión punitiva fue errónea como consecuencia de un nuevo hecho o de nuevas revelaciones, siempre y cuando ese desconocimiento de las circunstancias relevantes no fuese en ninguna medida imputables al afectado ${ }^{19}$. Por lo demás, el TEDH ha puntualizado que el error judicial debe obedecer realmente a nuevos hechos o revelaciones, no siendo aplicable este precepto - por tanto- a la revisión de condenas que obedezcan simplemente a una nueva valoración de las pruebas ya tenidas en cuenta en su momento ${ }^{20}$.

\subsection{Una importante modulación del régimen de responsabilidad patrimonial por acto administrativo ilegal}

Trasladado este requisito al ámbito administrativo, el precepto exige, además, para el ejercicio de este derecho, que la sanción administrativa haya

18 Vid. José Esteve PARDO, «Las asociaciones de configuración legal», Revista Española de Derecho Administrativo núm. 45 (1985).

${ }_{19}$ El caso objeto de la STEDH de 12 de junio de 2012, Poghosyan y Baghdasaryan c. Armenia, una de las pocas sentencias que ha aplicado directamente este precepto del Protocolo número 7, es expresivo al respecto. El Sr. Poghosyan fue condenado a varios años de cárcel por los delitos de asesinato y violación. Durante el cumplimiento de su condena, devenida firme, se descubrió al auténtico autor de los delitos. Al mismo tiempo, se probó en un proceso independiente que la confesión del Sr. Poghosyan fue obtenida bajo violencia por parte de los agentes de policía que lo detuvieron e interrogaron. La sentencia condenatoria del Sr. Poghosyan fue revisada y se le puso en libertad. En tales circunstancias, evidentemente, la confesión del Sr. Poghosyan no se consideró por el TEDH como inducción al error judicial imputable al condenado.

20 Vid. STEDH de 3 de julio de 2008, Metveyev c. Rusia, apartados 37-44. 
sido anulada por los motivos tasados y extraordinarios referidos. Y lo primero que hay que señalar es que esta exigencia del CEDH añade una importante modulación al régimen español de responsabilidad patrimonial de las Administraciones públicas.

El sistema español de responsabilidad patrimonial administrativa está formulado como garantía de los ciudadanos en el artículo 106.1 CE, según el cual los «particulares (...) tendrán derecho a ser indemnizados por toda lesión que sufran en cualquiera de sus bienes y derechos, salvo en los casos de fuerza mayor, siempre que la lesión sea consecuencia del funcionamiento de los servicios públicos». La opinión jurídica común, lastrada por la legislación del período inmediatamente preconstitucional y por la redacción de las normas legales posteriores y vigentes, ha sostenido que dicho sistema de responsabilidad - a diferencia del de Derecho privado y del que rige en otros países- se caracteriza por ser «objetivo». Y es que, en efecto, el artículo 32.1 de la Ley de Régimen Jurídico de la Administración del Estado, de 20 de julio de 1957, tras señalar lo que hoy casi en su literalidad señala la Constitución en el precepto recién citado, puntualizaba que la lesión indemnizable podía provenir de un funcionamiento tanto «normal» como «anormal de los servicios públicos». Y, en fin, el tenor del vigente artículo 32.1 de la Ley 40/2015, de 1 de octubre, del Sector Público (en adelante, LSP), se expresa en términos prácticamente idénticos: «Los particulares tendrán derecho a ser indemnizados por las Administraciones Públicas correspondientes, de toda lesión que sufran en cualquiera de sus bienes y derechos, siempre que la lesión sea consecuencia del funcionamiento normal o anormal de los servicios públicos salvo en los casos de fuerza mayor o de daños que el particular tenga el deber jurídico de soportar de acuerdo con la Ley». Es usual afirmar, por tanto, que en Derecho administrativo español la Administración pública responde siempre que: 1) se produzca un daño; y 2) este daño sea imputable a la Administración, con independencia de si la actuación dañosa de esta se realizó de forma diligente o culpable. En este sistema objetivo -suele sostenerse- , la Administración sólo queda exonerada en caso de fuerza mayor.

El caso es que la realidad, sin embargo, no es tan clara y lineal. Esa caracterización de la responsabilidad administrativa como una responsabilidad de tipo objetivo se ha construido teniendo a la vista fundamentalmente la actividad técnica o material de la Administración. Pero la Administración también puede provocar lesiones en la esfera patrimonial y personal de los administrados con su actividad jurídicamente formalizada, es decir, a través de actos administrativos que sean contrarios al ordenamiento jurídico ${ }^{21}$, y especialmente cuando

${ }^{21}$ Sobre los problemas de la responsabilidad patrimonial por actos administrativos ilegales en Derecho español, existen algunas obras doctrinales importantes que se extienden a lo largo del tiempo. Vid. Avelino Blasco Esteve, La responsabilidad de la Administración 
dichos actos son desfavorables o de gravamen (como lo son, precisamente, las sanciones administrativas).

En efecto, en relación con los actos administrativos, lo que sucede en la práctica es que no basta con que dichos actos resulten contrarios al ordenamiento jurídico o ilegales para que nazca, si hay daño individualizado y evaluable económicamente, un deber de indemnización a favor del perjudicado por parte de la Administración autora de dicho acto, como, sin embargo, sí sucedería en el seno de un sistema de responsabilidad rigurosamente objetivo. En concreto, para declarar responsable a la Administración, la jurisprudencia suele exigir en estos casos que la ilegalidad en que haya incurrido el acto lesivo en cuestión revista una especial intensidad. No basta, por tanto, cualquier ilegalidad para que la Administración autora del acto sea responsable del daño producido, sino que es necesario que esta haya incurrido en una «flagrante desatención normativa» ${ }^{22}$.

Existe, en consecuencia, una ilegalidad de «baja intensidad» o un margen de ilegalidad «admisible» o «tolerable», por decirlo así, dentro del cual la Administración no incurre en responsabilidad patrimonial, aunque el acto ilegal haya causado daños. Y ello no tanto porque se exija el requisito de la culpabilidad, como porque estaríamos en tal caso ante uno de los supuestos a los que se refiere el citado artículo 32.1 in fine LSP, en que el administrado tiene el «deber jurídico» de soportar el daño. Con todo, la jurisprudencia no es completamente uniforme, y pronunciamientos hay proclives a considerar cualquier grado de ilegalidad como título suficiente de imputación de responsabilidad administrativa ${ }^{23}$. A su vez, la doctrina también se ha sumado al debate, reproduciendo en paralelo las disparidades jurisprudenciales ${ }^{24}$. Por su parte, el legislador mismo da pábulo a la teoría del «margen de tolerancia» cuando en el citado artículo 32.1 LSP se añade un segundo y ambiguo párrafo en el que se dice: «La anulación en vía administrativa o por el orden

por actos administrativos, Civitas, Madrid, 1981 ( $1^{\mathrm{a}}$ ed.) y 1985 (2 ${ }^{\mathrm{a}}$ ed.); Luis MedinA AL$\mathrm{COZ}$, La responsabilidad patrimonial por acto administrativo, Civitas, Cizur Menor (Navarra), 2005; Gabriel DomÉNECH PASCUAL, «Responsabilidad patrimonial de la Administración por actos jurídicos ilegales», Revista de Administración Pública núm. 183 (2010); y Silvia DíEz SASTRE, «Culpa vs. ilegalidad: De nuevo sobre el fundamento de la responsabilidad por acto administrativo», Revista Española de Derecho Administrativo núm. 153 (2012).

22 Vid. Gabriel Doménech PAscual, ««Responsabilidad patrimonial de la Administración...», cit., p. 197.

${ }^{23}$ Vid. Silvia DíEz Sastre, «Culpa vs. Ilegalidad...», cit., pp. 7 y 8 (de la versión electrónica facilitada por la base de datos «Westlaw» de Thomson - Reuters, editora de la revista en la que se contiene el citado trabajo).

${ }^{24}$ Vid. Silvia DíEz SASTRE, «Culpa vs. Ilegalidad...», cit., pp. 8 y 9. 
jurisdiccional contencioso administrativo de los actos o disposiciones administrativas no presupone, por sí misma, derecho a la indemnización».

Sea como fuere, y volviendo al tema que nos ocupa, lo cierto es que la incorporación del artículo 3 del Protocolo 7 a nuestro ordenamiento tiene la virtualidad, en el ámbito que aquí nos afecta, de esquivar toda esta espinosa cuestión acerca del grado de ilegalidad de los actos administrativos a efectos indemnizatorios. En efecto, como venimos señalando y a tenor del citado artículo 3, basta con que la sanción impuesta «resulte posteriormente anulada (...) porque un hecho nuevo o nuevas revelaciones demuestren que ha habido error», y siempre que dicho error no fuere imputable al sancionado, para que este tenga derecho a ser indemnizado. La remisión contenida en el precepto a «la ley o al uso vigente en el Estado respectivo», hay que entenderla realizada a otros efectos, como son el cálculo de la indemnización o el procedimiento para la reclamación; y no para el supuesto de hecho mismo que da lugar al derecho, puesto que, en otro caso, el propio reconocimiento de este derecho por el texto internacional carecería de sentido y estaría vacío de contenido. En definitiva, cuando una sanción firme sea declarada ilegal por motivos ajenos al sancionado, el ordenamiento presume que a este se le han provocado unos daños que resultan imputables a la Administración y, por ende, indemnizables por esta. O, dicho de otra forma: se presume que el grado o tipo de invalidez del acto administrativo es lo suficientemente «flagrante» como para hacer incurrir a la Administración autora de aquel en responsabilidad patrimonial cuando: 1) dicho acto sea una sanción; 2) esa sanción hubiera devenido firme; y 3) esa sanción, después de haber devenido firme, hubiera sido anulada por algún vicio de invalidez que no fuera imputable, en todo o en parte, al mismo sancionado. Y ello -insistimos- no tanto porque así se deriva necesariamente de nuestro sistema de responsabilidad patrimonial administrativa como porque así lo exige en este concreto ámbito el artículo 3 del Protocolo 7.

\subsection{La revisión y revocación de sanciones administrativas firmes en Derecho español}

Ahora bien, ¿es posible, en nuestro Derecho, que una sanción administrativa que ya es firme sea anulada por los motivos a que se refiere el Protocolo? La respuesta es afirmativa, aunque el Derecho administrativo español permite la anulación de una sanción firme sólo en los siguientes casos: en vía administrativa, a resultas de una revisión de oficio o de un recurso extraordinario de revisión, y en vía judicial, a consecuencia de un recurso contencioso-administrativo de revisión de sentencias firmes. Cada uno de estos procedimientos y recursos son los que permiten, en el ordenamiento jurídicoadministrativo sancionador español, revisar una resolución sancionadora que haya devenido firme. Examinemos cada uno de ellos. 
En primer lugar, el artículo 106 LPAC permite que el interesado solicite a la Administración, en cualquier momento, la declaración de nulidad de los actos administrativos que hayan puesto fin a la vía administrativa o no hayan sido recurridos en plazo, si se estima que han incurrido en alguno de los supuestos de nulidad de los actos administrativos, recogidos en el artículo 47 LPAC.

Cualquiera de dichos supuestos de nulidad es susceptible de integrar el presupuesto de hecho determinante del derecho del artículo 3 del Protocolo núm. 7, pero uno de los más apropiados para ello es naturalmente el de la letra d) del artículo 47.1 LPAC: «Los [actos] que sean constitutivos de una infracción penal o se dicten como consecuencia de esta». Sería el caso de una sanción dictada en su momento como consecuencia de un delito (por ejemplo, una prevaricación administrativa), circunstancia que lógicamente sólo quedará acreditada con posterioridad, a resultas del correspondiente proceso penal.

Parcialmente coincidente con este cauce procedimental es el del recurso administrativo extraordinario de revisión, regulado en el artículo 125 LPAC, que tiene por objeto también actos administrativos firmes cuando concurra alguna de las siguientes circunstancias:

«a) Que al dictarlos se hubiera incurrido en error de hecho, que resulte de los propios documentos incorporados al expediente.

b) Que aparezcan documentos de valor esencial para la resolución del asunto que, aunque sean posteriores, evidencien el error de la resolución recurrida.

c) Que en la resolución hayan influido esencialmente documentos o testimonios declarados falsos por sentencia judicial firme, anterior o posterior a aquella resolución.

d) Que la resolución se hubiese dictado como consecuencia de prevaricación, cohecho, violencia, maquinación fraudulenta u otra conducta punible y se haya declarado así en virtud de sentencia judicial firme».

Pero tratándose la sanción de un acto desfavorable o de gravamen, también puede la Administración, de forma más sencilla y expeditiva, utilizar la potestad revocatoria que le confiere el artículo 109 LPAC, la cual puede ser ejercida por motivos de legalidad (no sólo de oportunidad) ${ }^{25}$. Sin embargo, de utilizarse este cauce para la revisión de la sanción firme, ha de quedar claro que la revocación obedece a motivos de legalidad, no de oportunidad, es

${ }^{25}$ La vía del artículo 109.1 LPAC está pensada, sobre todo, para la revocación por motivos de oportunidad, no de legalidad. Pero, como señala Manuel ReBollo PUIG, sería absurdo que la Administración pudiera revocar por esta vía un acto desfavorable por reputarlo inconveniente o inoportuno, y no cuando lo considerara ilegal. Vid. Derecho Administrativo, tomo II, dir. Manuel Rebollo Puig y Diego J. Vera Jurado, $3^{\mathrm{a}}$ ed., Tecnos, Madrid, 2018, p. 180. 
decir, porque la resolución sancionadora se dictó en su momento ilegalmente por la causa a que alude el Protocolo. En otro caso, la revocación de la sanción será en general lo efectiva que permita el ordenamiento jurídico nacional, pero no determinará el nacimiento del derecho a indemnización del artículo 3 del Protocolo 7.

Finalmente, como se ha apuntado, la anulación de la sanción firme también puede derivar de un proceso judicial, concretamente de un recurso contencioso-administrativo de revisión contra una sentencia firme confirmatoria de una sanción. Este recurso extraordinario está regulado en el artículo 102 de la Ley 29/1998, de 13 de julio, reguladora de la Jurisdicción Contencioso-Administrativa (en adelante LJCA), que permite revisar sentencias firmes siempre y cuando se dé alguno de los supuestos a los que se refiere su apartado 1:

«a) Si después de pronunciada [la sentencia] se recobraren documentos decisivos, no aportados por causa de fuerza mayor o por obra de la parte en cuyo favor se hubiere dictado.

b) Si hubiere recaído en virtud de documentos que, al tiempo de dictarse aquélla, ignoraba una de las partes haber sido reconocidos y declarados falsos o cuya falsedad se reconociese o declarase después.

c) Si habiéndose dictado en virtud de prueba testifical, los testigos hubieren sido condenados por falso testimonio dado en las declaraciones que sirvieron de fundamento a la sentencia.

d) Si se hubiere dictado sentencia en virtud de cohecho, prevaricación, violencia u otra maquinación fraudulenta».

En cualquier caso, el derecho de indemnización no nacerá hasta que, estimado el recurso extraordinario y devueltos los autos al juez o tribunal del que procedan, las partes usen entonces de su derecho y obtengan de este la anulación de la sanción originariamente recurrida (cfr. art. 516 de la Ley de Enjuiciamiento Civil).

\section{TITULARIDAD Y OBJETO DEL DERECHO}

\section{Personas físicas y también personas morales o jurídicas}

Establece el artículo 3 del Protocolo 7 que el titular del derecho es la «persona que haya sufrido la pena» como consecuencia de la condena anulada. En nuestro caso eso significa que sólo podrán ser titulares de este derecho quienes efectivamente hayan sufrido la sanción administrativa impuesta por la resolución sancionadora anulada a través de alguno de los mecanismos examinados anteriormente.

Además, como en nuestro Derecho sancionador pueden ser sujetos responsables no sólo las personas físicas, sino también las jurídicas, cabe plantearse si pueden ser titulares del derecho de indemnización reconocido en el Protocolo 
las personas jurídicas. Es más: ¿y las entidades sin personalidad a las que, a veces, las normas atribuyen cierta subjetividad a efectos sancionadores?

En cuanto a las personas jurídicas, la jurisprudencia del TEDH admite la titularidad de los derechos protegidos por el Convenio por parte de dichas entidades, en la misma línea en que lo hacen las tradiciones jurídicas de los Estados parte en relación con los derechos fundamentales reconocidos por sus Constituciones. Al respecto es claro y contundente el artículo 34 CEDH: «El Tribunal podrá conocer de una demanda presentada por cualquier persona física, organización no gubernamental o grupo de particulares que se considere víctima de una violación, por una de las Altas Partes Contratantes, de los derechos reconocidos en el Convenio o sus protocolos...». De ahí que pueda afirmarse que los únicos derechos humanos que no pueden reconocerse a las personas jurídicas son aquellos cuyos elementos de aplicación están ligados a los atributos propios de las personas físicas o naturales ${ }^{26}$. Con estos límites y algún otro (como el de que debe tratarse de personas jurídicas privadas, no públicas), el reconocimiento de los derechos protegidos por el Convenio a las personas jurídicas ha sido una constante en la jurisprudencia del $\mathrm{TEDH}^{27}$. Por ejemplo, el Tribunal afirmó con fuerza esta doctrina en 1997, en relación con la Iglesia católica en Grecia, a la que las autoridades griegas no reconocían personalidad jurídica para actuar ante los órganos jurisdiccionales, y en 2000, en otro asunto relativo a una asociación religiosa judía por lo que se refiere al ejercicio de la libertad religiosa, y en la que afirmó: «El Tribunal considera, al igual que la Comisión, que un órgano eclesial o religioso puede, como tal, ejercer en nombre de sus fieles los derechos garantizados por el artículo 9 del Convenio («mutatis mutandis», Sentencia Iglesia Católica de la Canée contra Grecia de 16 diciembre 1997, Repertorio de sentencias y resoluciones, 1997-VIII, pg. 2856, ap. 31). En este caso, cualquiera que sea la religión considerada, una comunidad de fieles debe constituirse, en derecho francés, bajo la forma jurídica de asociación de culto, cuyo caso es el de la demandante ${ }^{28}$. En definitiva, ningún problema hay aquí en admitir a

${ }^{26}$ En esta línea, vid. Christoph Grabenwarter, European Convention on Human Rights. Comentary, cit., p. 3, citando los derechos a la vida, a la libertad y seguridad, a la vida privada y familiar y al matrimonio, así como la prohibición de tortura y tratos inhumanos y degradantes y de la pena de muerte.

27 Vid. Pablo Antonio Fernández SÁnchez, «II. El alcance de las obligaciones», en La Europa de los Derechos. El Convenio Europeo de Derechos Humanos, coord. Javier García Roca y Pablo Santolaya, Centro de Estudios Políticos y Constitucionales, Madrid, 2005, p. 58.

28 Apartado 72 de la STEDH de 27 de junio de 2000, Chaare Shalom Ve Tsedek c. Francia. Un poco antes, mediante Sentencia de 6 de abril de 2000, Comingersoll, S. A. c. Portugal, el TEDH había afirmado también expresamente la titularidad de los derechos 
las personas jurídicas como posibles titulares del derecho reconocido en el artículo 3 del Protocolo 7.

Tampoco parecen existir dificultades insalvables en relación con las entidades sin personalidad. Como se ha visto, el citado artículo $34 \mathrm{CEDH}$ habla de «grupo de particulares». Y, a su vez, el artículo 28.1 LSP enuncia entre los posibles responsables de infracciones administrativas, «cuando una Ley les reconozca capacidad de obrar, los grupos de afectados, las uniones y entidades sin personalidad jurídica y los patrimonios independientes o autónomos». Por tanto, en la medida en que el sujeto que haya padecido la sanción anulada (por ejemplo, multa, cierre de establecimiento o de actividad, etc.) sea -a tenor de lo previsto por la ley administrativa correspondiente- una entidad sin personalidad (por ejemplo, una comunidad de bienes) ${ }^{29}$, será dicha entidad como tal la que tendrá derecho a la indemnización a que se refiere el Protocolo 7.

\section{La indemnización objeto del derecho}

El derecho reconocido en el artículo 3 del Protocolo 7 tiene por objeto una indemnización «conforme a la Ley o al uso vigente en el Estado respectivo». Como se ha señalado, esta remisión tan sólo se refiere a la forma de valorar la indemnización y al procedimiento concreto para reclamarla, así como a la modalidad de hacer efectiva esa indemnización (si en dinero o en especie). En cuanto a esto último, la legislación administrativa española prevé que la indemnización en dinero pueda sustituirse por una compensación en especie o ser abonada mediante pagos periódicos, aunque siempre supeditado todo ello a que exista acuerdo con el interesado (art. 34.4 LSP).

En cualquier caso, esta remisión obliga a tener en cuenta las normas que disciplinan en nuestro Derecho la responsabilidad patrimonial de las Administraciones públicas, recogidas en la LSP y en la LPAC, en su vertiente material y procedimental, respectivamente.

\subsection{De daños patrimoniales y no patrimoniales}

En tal sentido, es indemnizable «toda lesión» que el sancionado haya sufrido «en cualquiera de sus bienes y derechos» (artículo 32.1 LSP),

procesales del artículo 6 CEDH por parte de una sociedad mercantil, a la que se reconoció incluso una indemnización por los daños morales derivados de su vulneración.

${ }^{29}$ En cualquier caso, sobre el alcance del citado artículo 28.1 LSP y su articulación con las diferentes leyes sectoriales que prevén la responsabilidad sancionadora de este tipo de entidades, así como los problemas que todo ello puede generar, vid. Manuel ReBOLLO PUIG, «Responsabilidad sancionadora de personas jurídicas, entes sin personalidad y administradores», en Ius et Veritas núm. 53 (2016), pp. 233-237. 
siempre y cuando - eso sí- el daño alegado sea «efectivo, evaluable económicamente e individualizado con relación a una persona o grupo de personas» (artículo 32.2 LSP). Esta última aclaración no implica, sin embargo, que el daño indemnizable haya de ser exclusivamente de carácter patrimonial; también deben entenderse incluidos los daños no patrimoniales, incluidos los morales, cuando los haya, e incluso la denominada «pérdida de la oportunidad».

En cuanto a los daños patrimoniales, dispone el artículo 34.2 LSP que la «indemnización se calculará con arreglo a los criterios de valoración establecidos en la legislación fiscal, de expropiación forzosa y demás normas aplicables, ponderándose, en su caso, las valoraciones predominantes en el mercado». Sobre los daños patrimoniales indemnizables como consecuencia de una sanción posteriormente anulada es ilustrativo el caso resuelto por la STS de 10 de abril de 2012 (Sala de Contencioso-Administrativo, recurso contencioso-administrativo núm. 451/2010). El recurrente era magistrado presidente de sección en una Audiencia Provincial en el momento en el que fue sancionado por el Consejo General del Poder Judicial, en el año 2006, con suspensión de funciones por tiempo de siete meses como autor de una falta muy grave tipificada en la Ley Orgánica del Poder Judicial, por retraso injustificado en la resolución de asuntos. Cumplida íntegramente la sanción, la Comisión Permanente del Consejo declaró la aptitud para el reingreso en el servicio activo del magistrado sancionado, con la obligación de participar en cuantos concursos se anunciasen para la provisión de plazas de su categoría, solicitando todas las vacantes que se relacionen hasta obtener destino en propiedad. Al mes siguiente se publicó en el BOE anuncio de concurso para la provisión de determinados cargos judiciales, en el que participó el magistrado recurrente, obteniendo destino en un juzgado de primera instancia e instrucción. Dos años más tarde, en un recurso contencioso-administrativo interpuesto por el recurrente, el Tribunal Supremo anuló la sanción que se le había impuesto en 2006, al apreciar caducidad del procedimiento sancionador tramitado en su momento, y reconoció al recurrente el derecho a reintegrarse en el puesto de presidente de sección de la Audiencia Provincial y a las remuneraciones dejadas de percibir con sus intereses legales. La Administración abonó los salarios dejados de percibir, devolvió al sancionado su lugar en el escalafón y le ofreció la posibilidad de reincorporarse a su primitiva plaza de presidente de sección de la Audiencia Provincial. El sancionado rehusó, sin embargo, a esta última posibilidad. Posteriormente, el recurrente presentó ante el Consejo General del Poder Judicial reclamación de responsabilidad patrimonial por los daños sufridos como consecuencia del traslado de localidad a que se vio abocado una vez incorporado al servicio activo. El Consejo denegó la reclamación, alegando que el sancionado había rehusado regresar a la localidad en la que originalmente estaba prestando servicios. Sin 
embargo, el Tribunal Supremo, en el recurso contencioso-administrativo interpuesto por el reclamante, falló a favor de este, señalado que el obligado traslado a una nueva plaza le había ocasionado evidentes perjuicios, con independencia de que, a partir de la fecha en que rehusó regresar al puesto originario, se pudiera entender que cesaba la producción de dichos daños: «(...) se declara el derecho del recurrente a ser indemnizado (...) en virtud de la responsabilidad patrimonial de esta Administración Pública, como consecuencia de la anulación de la sanción disciplinaria impuesta, en la cuantía de los gastos de traslado forzoso una vez obtenida plaza en [el juzgado de primera instancia e instrucción] desde [la localidad de la sede de la Audiencia Provincial] y los referidos al alquiler de la casa en esa localidad gallega con todos los gastos de alojamiento, hotel y de suministros de vivienda consumidos, limitados al período ya mencionado que se comprende entre la toma de posesión y la admisión por parte de la Comisión Permanente de la renuncia por el interesado de la restitución a la plaza en la Audiencia Provincial de (...)» $\left(\mathrm{FJ} 8^{\circ}\right)$.

Por otra parte, aunque pueda no ser normal en el caso de la anulación de sanciones, también son indemnizables los daños no patrimoniales de carácter personal, sobre los que dispone también el citado artículo 34.2 LSP que «se podrá tomar como referencia la valoración incluida en los baremos de la normativa vigente en materia de Seguros obligatorios y de la Seguridad Social». Lo habitual -aunque no preceptivo-en este punto es tomar en consideración, como orientativos, los criterios y el baremo contenidos en el Real Decreto Legislativo 8/2004, de 29 de octubre, por el que se aprueba el texto refundido de la Ley sobre Responsabilidad Civil y Seguro en la Circulación de Vehículos a Motor ${ }^{30}$.

\subsection{De daños morales y de la «pérdida de oportunidad»}

Pero los daños extrapatrimoniales incluyen también aquellos daños no susceptibles de valoración ni de constatación médica salvo que se conviertan en una enfermedad, es decir, los que tradicionalmente se han denominado daños morales (como la angustia, la pena, la zozobra, la vergüenza, etc.) ${ }^{31}$. En relación precisamente con este tipo de daños, la STEDH de 12 de junio de

30 Vid. María de la Paz SÁnchez GonzÁlez, «Responsabilidad de la Administración por daños morales», en La responsabilidad patrimonial de la Administración pública, tomo I, Tomás Quintana López (dir.) y Ana Belén Casares Marcos (coord.), 2a ed., Tirant Lo Blanch, Valencia, 2013, pp. 781 y 782.

31 Vid. Tomás CANO CAMPOS, «La transmisión mortis causa del derecho a ser indemnizado por los daños no patrimoniales causados por la Administración», Revista de Administración Pública núm. 191 (2013), p. 120. 
2012, Poghosyan y Baghdasaryan c. Armenia, ha tenido ocasión de declarar expresamente que el derecho reconocido en el artículo 3 del Protocolo número 7 del Convenio cubre específicamente los daños morales, incluso aunque el Derecho nacional no lo tenga previsto ${ }^{32}$.

En cualquier caso, también estos daños, aun no valorables, sí son desde hace tiempo en el Derecho español, tanto en el ámbito civil como en el administrativo, evaluables económicamente y, como tales, objeto de indemnización. Ante la diversidad de pareceres doctrinales y jurisprudenciales sobre la noción de daño moral, a esta - tal y como la hemos descrito- habría que añadirle alguna nota que la restringiera más rigurosamente, de forma que la lesión psicológica en que el daño moral consiste debe derivar de la lesión no de cualquier bien, sino de los denominados bienes de la personalidad (honor, reputación, imagen, intimidad, etc. $)^{33}$. Tratándose de daños que repercuten no en bienes materiales sino inmateriales de la persona, como el honor o la intimidad, su valoración a efectos de fijar la cantidad indemnizable no puede apoyarse en criterios perfectamente objetivables. La Administración -y en su caso el órgano judicial- deberá hacer, por tanto, una estimación ad casum basada en criterios razonables, tales como el tiempo transcurrido entre la

${ }^{32}$ En concreto, frente a las alegaciones de las autoridades armenias relativas a que la reparación del injustamente condenado se había realizado a través de una disculpa gubernativa formal, conforme a la legislación armenia para tales casos, el TEDH consideró insuficiente dicha práctica nacional y condenó a las autoridades estatales armenias a indemnizar con 30.000 euros al demandante: «51. En cuanto al respeto de las garantías del artículo 3 del Protocolo núm. 7, el Tribunal estima que, aunque esta disposición garantiza el pago de una indemnización conforme a la Ley o a la práctica del Estado concernido, esto no significa que no se abone indemnización alguna cuando el derecho o la práctica internas no lo prevean (ver igualmente el apartado 25 de la exposición de motivos del Protocolo núm. 7 al Convenio, apartado 30 supra). Así mismo, el Tribunal estima que la finalidad del artículo 3 del Protocolo no es simplemente cubrir cualquier pérdida financiera causada por una condena sino también ofrecer a una persona condenada tras un error judicial una reparación por el daño moral sufrido, como el sentimiento de miseria o angustia, el disgusto y la degradación de la calidad de vida. Ahora bien, en este caso, el demandante no dispuso de ninguna reparación. (...) 63. El Tribunal no percibe vínculo alguno de causalidad entre la violación constatada y el perjuicio material alegado y rechaza esta demanda. En cambio, considera que procede conceder al demandante 30.000 EUR en concepto de daño moral». También la doctrina afirmaba la inclusión de los daños morales en este derecho del Protocolo número 7: vid., por ejemplo, Isabel Perelló Doménech, «El derecho a ser indemnizado en supuestos de error judicial», en La Europa de los Derechos. El Convenio Europeo de Derechos Humanos, coord. Javier García Roca y Pablo Santolaya, Centro de Estudios Políticos y Constitucionales, Madrid, 2005, p. 444; y -con posterioridad a la sentencia citada- Christoph GraBENWARTER, European Convention on Human Rights. Comentary, cit., p. 433.

33 Vid. María de la Paz SÁnchez GonzÁlez, «Responsabilidad de la Administración por daños morales», cit., pp. 772 y 773 . 
firmeza de la sanción y su anulación, la naturaleza y contenido de la sanción anulada, su publicidad, el impacto negativo sobre la reputación y prestigio del afectado, las circunstancias que condujeron al error padecido por el órgano sancionador, $\mathrm{etc}^{34}$. Criterios generales de este tipo son los que ofrece el artículo 9 de la LO 1/1982, de Protección Civil del Derecho al Honor, a la Intimidad y a la propia Imagen, y que son los que -según la jurisprudenciadebe manejar la Administración cuando ocasiona lesiones al honor (han sido frecuentes, por ejemplo, como consecuencia de comunicados de prensa sobre el progreso de operaciones policiales o investigaciones de determinados hechos ilícitos) $)^{35}$.

En materia específicamente sancionadora, lo que podríamos denominar «daño reputacional» ha sido tenido en cuenta por algunos pronunciamientos judiciales. Al respecto puede citarse últimamente el caso resuelto por la STSJ de Castilla y León, Valladolid (Sala de lo Contencioso-Administrativo), núm. 612/2017, de 19 mayo. Un radiofísico del Complejo Asistencial de Burgos fue sancionado por la Gerencia de Salud del Área sanitaria correspondiente, imponiéndosele la sanción de traslado forzoso con cambio de localidad. No llegó a verificarse dicho traslado porque se acogió a una excedencia por interés particular, trasladándose a Alicante. Al cabo de un tiempo, el órgano judicial resolvió el recurso contencioso-administrativo interpuesto por el sancionado contra la medida disciplinaria, anulando dicha sanción. El sancionado reclamó con posterioridad y sin éxito una indemnización por los daños de carácter moral. Si bien no con el alcance pretendido, el TSJ dio la razón al reclamante sobre la base del siguiente razonamiento: «En conclusión, teniendo en cuenta lo expuesto sobre el limitado alcance del descrédito profesional y daño psíquico secuente a la sanción y que, ello no obstante, se atribuyó al actor de modo antijurídico la comisión de hechos por todos calificados de muy graves - percepción de cantidades en concepto de guardias o prolongación de jornadas, y no realizadas, durante los años 2006, 2007 y 2008; incumplimiento de sus obligaciones como Jefe del Servicio en relación con las licencias de supervisores, así como en la vigilancia radiológica de los trabajadores expuestos a instalaciones radioactivas; realizar anotaciones falsas en los libros de operaciones de aceleración lineal, bomba de cobalto y Medicina Nuclear-, con el resultado de una sanción de traslado forzoso

${ }^{34}$ A título ilustrativo y en relación con otro derecho distinto -en materia de legalidad penal-, la STEDH de 21 de octubre de 2013, del Río Prada c. España, concedió una indemnización de 30.000 euros en concepto de daño moral por la aplicación retroactiva de la conocida como «doctrina Parot» y por la que la demandante fue puesta en libertad cinco años más tarde de lo que le hubiera correspondido.

35 Vid. María de la Paz SÁnchez GonzÁlez, «Responsabilidad de la Administración por daños morales», cit., pp. 785-787. 
igualmente antijurídica, procede estimativamente valorar el en todo caso innegable daño moral inherente a dicha antijurídica imputación padecido desde febrero de 2010, de imposición de sanción, hasta febrero de 2012, de anulación por sentencia firme, en la suma de $30.000 €$.» (FJ 4 ${ }^{\circ}$ ).

Finalmente, también se ha abierto camino en los últimos años la posibilidad de indemnizar la «pérdida de la oportunidad», la privación de la expectativa de obtener una ventaja más o menos incierta, sufrida por el particular e imputable a la Administración ${ }^{36}$. La denominada «teoría de la pérdida de la oportunidad»-esgrimida por la jurisprudencia sobre todo en el ámbito de la responsabilidad sanitaria- podría resultar especialmente adecuada para ser aplicada también en el campo disciplinario, en el que la índole de las sanciones más frecuentes (suspensión de funciones, por ejemplo), puede conllevar en algunos casos la privación de optar a ciertos beneficios o ventajas de carácter profesional.

\section{PROCEDIMIENTO}

1. 'La vía administrativa: revisión de oficio o reclamación de responsabilidad patrimonial de la Administración

El procedimiento para ejercer este derecho será también el previsto en «la Ley o el uso vigente del Estado respectivo». En nuestro caso caben varias posibilidades. La primera es la acumulación de la pretensión indemnizatoria a la de anulación de la sanción ilegal en vía administrativa si lo que se ejerce contra la sanción ilegal es una revisión de oficio por ser nula de pleno derecho. En efecto, el artículo 106.4 LPAC dispone: «Las Administraciones Públicas, al declarar la nulidad de una disposición o acto, podrán establecer, en la misma resolución, las indemnizaciones que proceda reconocer a los interesados...».

La segunda posibilidad, y más general, consiste en la reclamación de responsabilidad patrimonial a través del procedimiento administrativo común regulado en la LPAC con las especialidades establecidas por dicha norma en materia de responsabilidad patrimonial de la Administración. En tal caso, el plazo para solicitar la indemnización es de un año desde la notificación de la resolución administrativa o la sentencia «definitiva» [rectius: «firme» $\left.{ }^{37}\right]$ que

${ }^{36}$ Sobre esta teoría, vid. Luis Medina Alcoz, La teoría de la pérdida de oportunidad: estudio doctrinal y jurisprudencial de derecho de daños público y privado, Aranzadi, Cizur Menor (Navarra), 2007, y del mismo autor «La teoría de la pérdida de oportunidad», Revista Española de la Función Consultiva núm. 16 (2011).

37 Aunque la Ley no dice «firme», sino «definitiva», lo cual no es lo mismo, hay que entender que el momento a quo del citado plazo es el de la adquisición de firmeza por 
haya anulado la sanción firme en cuestión (art. 67.1, segundo párrafo, LPAC).

Una vez agotada la vía administrativa por cualquiera de estos dos caminos, se abre la posibilidad de acudir a la vía judicial. Aunque en relación con esta hay que hacer dos observaciones. La primera es que existe aquí también la posibilidad de acumular la pretensión indemnizatoria al recurso contencioso-administrativo que se haya presentado contra la denegación de revisión en vía administrativa, y ello aunque en esta no se hubiera formulado pretensión indemnizatoria alguna ${ }^{38}$. La segunda observación es de calado más amplio y se refiere al siguiente interrogante: si se considerara que el artículo 3 del Protocolo número 7 del CEDH reconoce no sólo un derecho convencional sino también, por vía de integración ex artículo 10.2 CE, un derecho fundamental a efectos constitucionales internos, la vía judicial disponible sería no sólo la representada por el recurso contencioso-administrativo general, sino que el afectado dispondría también, por un lado y como alternativa, del procedimiento judicial especial y sumario para la tutela de los derechos fundamentales, previsto en el artículo 53.2 CE y desarrollado actualmente para el ámbito contencioso-administrativo en los artículos 114121 LJCA, y además, por otro lado y una vez agotada la vía judicial, del recurso de amparo, previsto también en el artículo 53.2 CE y desarrollado en los artículos 41-58 de la LO 2/1979, de 3 de octubre, del Tribunal Constitucional. ¿Pero es realmente así? ¿Es el derecho reconocido en el artículo 3 del Protocolo un derecho fundamental en este sentido? Veámoslo.

\section{El derecho del artículo 3 del Protocolo 7, ¿derecho fundamental a efectos constitucionales internos?}

A favor de que el derecho indemnizatorio reconocido en el analizado artículo 3 es, además de un derecho convencional vinculante para España en el ámbito internacional, un derecho fundamental a efectos constitucionales

parte del acto o sentencia anulatorios, es decir, la expiración del plazo para interponer contra ellos los recursos ordinarios procedentes. Vid., sobre el particular, Lucía ALARCóN SOTOMAYOR, «El plazo para pedir responsabilidad patrimonial a las Administraciones públicas», en La responsabilidad patrimonial de la Administración Pública, tomo I, Tomás Quintana López (dir.) y Anabelén Casares Marcos (coord.), 2ª ed., Tirant Lo Blanch, Valencia, 2013, pp. 197-199.

38 En efecto, dispone el artículo 31 LJCA: «1. El demandante podrá pretender la declaración de no ser conformes a Derecho y, en su caso, la anulación de los actos y disposiciones susceptibles de impugnación (...) 2. También podrá pretender el reconocimiento de una situación jurídica individualizada y la adopción de las medidas adecuadas para el pleno restablecimiento de la misma, entre ellas la indemnización de los daños y perjuicios, cuando proceda». 
internos, está la denominada cláusula de apertura del artículo 10.2 CE, según la cual las «normas relativas a los derechos fundamentales y a las libertades que la Constitución reconoce se interpretarán de conformidad con la Declaración Universal de Derechos Humanos y los tratados y acuerdos internacionales sobre las mismas materias ratificados por España». En este sentido, puede recordarse cómo el TC ha ido concretando algunos de los derechos y garantías procedimentales, penales y sancionadores, reconocidos en el artículo $24.2 \mathrm{CE}$ a la luz del artículo 6 del $\mathrm{CEDH}^{39}$. En esta línea, podría interpretarse ex artículo 10.2 CE que el derecho reconocido en el artículo 3 del Protocolo 7 del CEDH ha pasado a constituir uno de los derechos fundamentales de defensa reconocidos en el artículo 24.2 CE, relacionado concretamente con el derecho a utilizar los medios de prueba pertinentes para la defensa. En efecto, el tipo de error al que alude el referido artículo 3 es el que se produciría como consecuencia de la privación de elementos exculpatorios que, por el motivo que sea, quedaron fuera del alcance del imputado o sancionado en el momento del procedimiento sancionador y en el momento ulterior de los recursos ordinarios correspondientes, y que hubieran resultado eficaces para el éxito de su defensa. En consecuencia, lo que se pretendería con este derecho indemnizatorio es reparar, no tanto un daño patrimonial cuanto un daño de carácter moral, el ocasionado a un derecho de la persona como es el derecho fundamental de defensa.

No parece, sin embargo, que pueda sostenerse una conclusión como esta. En primer lugar, es oportuno recordar que no todos los derechos reconocidos en los tratados y acuerdos internacionales ratificados por España en materia de derechos humanos han sido reconducidos por nuestro TC a alguno de los derechos fundamentales reconocidos por la Constitución. Así ha sucedido, por ejemplo, y precisamente en materia punitiva, con la retroactividad de las normas sancionadoras favorables, que el TC no entiende incluida en el derecho fundamental a la legalidad penal del artículo 25.1 CE, y ello pese a que dicha retroactividad es reconocida como derecho expresamente en el artículo 15.1 in fine del Pacto Internacional de Derechos Civiles y Políticos y el TEDH la considera implícitamente incluida en el artículo 7.1 CEDH desde la Sentencia Scoppola c. Italia de 17 de septiembre de 2009. Pues bien, aunque

39 Vid. Lucía Alarcón Sotomayor, El procedimiento administrativo sancionador y los derechos fundamentales, Civitas, Cizur Menor (Navarra), 2007, pp. 29-37; Francisco DíAz Fraile, Derecho Penal y Derecho Administrativo Sancionador. Garantías y límites en la jurisprudencia del TEDH, Tirant lo Blanch, Valencia, 2015, y Derecho administrativo sancionador. Análisis a la luz de la jurisprudencia del Tribunal Constitucional y del Tribunal Europeo de Derechos Humanos, Atelier, Barcelona, 2016; y Ciro Milione FuGALI, El derecho a la tutela judicial efectiva en la jurisprudencia del Tribunal Europeo de Derechos Humanos, Tirant lo Blanch, Valencia, 2015. 
en sentencias ciertamente ya algo antiguas, el TC afirma que la referida retroactividad tiene cierto anclaje constitucional, pero no como derecho fundamental en sentido estricto, sino como principio derivado de la seguridad jurídica ex artículo 9.3 CE, y no goza - por tanto- de acceso a la vía de protección del recurso de amparo ${ }^{40}$. En segundo lugar, el TC ha negado expresamente que la garantía indemnizatoria establecida en el artículo $121 \mathrm{CE}$ frente a los errores judiciales ${ }^{41}$, y muy cercana -como es evidente- al derecho del artículo 3 del Protocolo 7, constituya un derecho fundamental ${ }^{42}$. Y, en tercer lugar, el TC ha declarado con carácter más general que la vía del artículo 10.2 CE sirve para interpretar derechos ya reconocidos por nuestra Constitución, pero no para introducir otros nuevos no previstos en ella ${ }^{43}$. A este propósito no cabe duda de que el del artículo 3 del Protocolo 7 es un derecho de nueva factura, con sustantividad propia. No está previsto como tal en nuestra Constitución. Y aunque relacionado con el derecho de defensa, no busca directamente la tutela de este, sino, más bien, la compensación de los daños experimentados por quien precisamente, y como consecuencia de ello, no pudo gozar de dicha tutela en el ámbito punitivo como condenado o sancionado. Al menos a la luz de la actual jurisprudencia constitucional, no sirve, en definitiva, por su autonomía y sustantividad propia, para «ensanchar» ex artículo 10.2 CE el alcance de alguno de los derechos fundamentales reconocidos por nuestra Constitución.

Esta conclusión no obsta, sin embargo, a que el derecho de indemnización reconocido en el artículo 3 del Protocolo 7 sea, en el seno de nuestro ordenamiento, un derecho subjetivo en sentido estricto, protegido por la legalidad ordinaria -so pena de infringir nuestras obligaciones internacionales- , y capaz de sustentar -en último extremo y agotadas las vías internas de recursos- una demanda ante el TEDH, tal y como prevén los artículos 34 y $35 \mathrm{CEDH}$.

40 Vid. SSTC 15/1981, de 7 de mayo, 62/1982, de 15 de octubre, 131/1986, de 29 de octubre, 22/1990, de 15 de febrero, entre otras, y los AATC 471/1984, de 24 de julio, 876/1986, de 29 de octubre, 226/1990, de 4 de junio, y 339/1992, de 16 de noviembre.

${ }^{41}$ Establece este artículo: «Los daños causados por error judicial, así como los que sean consecuencia del funcionamiento anormal de la Administración de Justicia, darán derecho a una indemnización a cargo del Estado, conforme a la ley».

42 Vid. STC 40/1988, de 10 de marzo: «Ha de observarse además que aunque la Constitución configura la indemnización por error judicial o por funcionamiento anormal de la Administración de Justicia como un derecho, no lo ha configurado, a diferencia de lo que hace, por ejemplo, la Constitución italiana, como un derecho fundamental, lo que hace imposible, de conformidad con el art. 53 de la Constitución, su alegación y su resolución en esta vía de amparo» $\left(\mathrm{FJ}^{\circ}\right)$.

${ }^{43}$ Vid. Luis María DíEz-PICAzo, Sistema de derechos fundamentales, $4^{\mathrm{a} e d}$., Civitas, Cizur Menor (Navarra), 2013, p. 156, y la jurisprudencia constitucional ahí citada. 


\section{CONCLUSION.}

Pese a las apariencias, el derecho de indemnización reconocido en el artículo 3 del Protocolo número 7 del CEDH no es aplicable sólo a la anulación de condenas penales firmes, sino también de sanciones administrativas firmes. Esto tiene efectos importantes en el plano jurídico-administrativo interno. El primero es que, aunque en el Derecho español está plenamente asentada la responsabilidad patrimonial de los poderes públicos en general, y de la Administración en particular, el reconocimiento convencional de este derecho tiene la virtualidad de despejar en el ámbito sancionador las dudas que existen en nuestro sistema resarcitorio público acerca de cuándo se entiende producida la responsabilidad por acto administrativo ilegal. A tenor de lo dispuesto en el Convenio, al menos en un caso nunca habrá dudas: cuando se anule una sanción administrativa firme por motivos ajenos al sancionado. En tal caso, la ilegalidad del acto administrativo en cuestión -de la sanción-se presume que es lo suficientemente grave como hacer incurrir a la Administración autora del acto en responsabilidad patrimonial. La remisión del precepto convencional a la costumbre y legislación de los Estados parte lo es sólo a efectos del cálculo de la indemnización y del procedimiento de ejercicio. Finalmente, también es importante el hecho de que, aunque no se trata de un derecho fundamental a efectos constitucionales internos, sí que es un derecho subjetivo plenamente ejercitable ante las Administraciones españolas y los tribunales ordinarios, además de contar con la garantía última de su tutela por el TEDH.

\section{BIBLIOGRAFÍA}

ABerasturi Gorriño, U., «Comentario al artículo 3 del Protocolo número 7», en Convenio Europeo de Derechos Humanos. Comentario sistemático, $2^{\mathrm{a}}$ ed., dir. Iñaki Lasagabaster Herrarte, Civitas, Cizur Menor (Navarra), 2009

Alarcón Sotomayor, L., «El plazo para pedir responsabilidad patrimonial a las Administraciones públicas», en La responsabilidad patrimonial de la Administración Pública, tomo I, Tomás Quintana López (dir.) y Anabelén Casares Mar$\cos$ (coord.), $2^{\mathrm{a}}$ ed., Tirant Lo Blanch, Valencia, 2013

_- El procedimiento administrativo sancionador y los derechos fundamentales, Civitas, Cizur Menor (Navarra), 2007

Bertazzo, S., «El Derecho Administrativo Sancionador a la luz del Convenio Europeo de Derechos Humanos», en Revista General de Derecho Administrativo núm. 39 (2015)

Blasco Esteve, A., La responsabilidad de la Administración por actos administrativos, Civitas, Madrid, 1981 ( $1^{\mathrm{a}}$ ed.) y 1985 ( $2^{\mathrm{a}}$ ed.)

CANO CAMPOS, T., «La transmisión mortis causa del derecho a ser indemnizado por los daños no patrimoniales causados por la Administración», Revista de Administración Pública núm. 191 (2013) 
Díaz Fraile, F., Derecho administrativo sancionador. Análisis a la luz de la jurisprudencia del Tribunal Constitucional y del Tribunal Europeo de Derechos Humanos, Atelier, Barcelona, 2016

— Derecho Penal y Derecho Administrativo Sancionador. Garantías y límites en la jurisprudencia del TEDH, Tirant lo Blanch, Valencia, 2015,

DíEz SASTRE, S., «Culpa vs. ilegalidad: De nuevo sobre el fundamento de la responsabilidad por acto administrativo», Revista Española de Derecho Administrativo núm. 153 (2012)

DomÉNECH PASCUAL, G., «Responsabilidad patrimonial de la Administración por actos jurídicos ilegales», Revista de Administración Pública núm. 183 (2010)

EsteVe PARDo, J., «Las asociaciones de configuración legal», Revista Española de Derecho Administrativo núm. 45 (1985)

FERNÁNDEZ SÁNCHEZ, P.A., «II. El alcance de las obligaciones», en La Europa de los Derechos. El Convenio Europeo de Derechos Humanos, coord. Javier García Roca y Pablo Santolaya, Centro de Estudios Políticos y Constitucionales, Madrid, 2005

Grabenwarter, C., European Convention on Human Rights. Comentary, C. H. Beck - Hart - Nomos, Freiburg, 2014

LóPez Benítez, M., Naturaleza y presupuestos constitucionales de las relaciones especiales de sujeción, Civitas, Madrid, 1994

Medina Alcoz, L., La responsabilidad patrimonial por acto administrativo, Civitas, Cizur Menor (Navarra), 2005

— L L teoría de la pérdida de oportunidad: estudio doctrinal y jurisprudencial de derecho de daños público y privado, Aranzadi, Cizur Menor (Navarra), 2007

—_, «La teoría de la pérdida de oportunidad», Revista Española de la Función Consultiva núm. 16 (2011)

Milione Fugali, C., El derecho a la tutela judicial efectiva en la jurisprudencia del Tribunal Europeo de Derechos Humanos, Tirant lo Blanch, Valencia, 2015

Perelló Doménech, I., «El derecho a ser indemnizado en supuestos de error judicial», en La Europa de los Derechos. El Convenio Europeo de Derechos Humanos, coord. Javier García Roca y Pablo Santolaya, Centro de Estudios Políticos y Constitucionales, Madrid, 2005

Rebollo Puig, M., «La revisión de oficio», en Derecho Administrativo, tomo II, dir. Manuel Rebollo Puig y Diego J. Vera Jurado, $3^{\text {a }}$ ed., Tecnos, Madrid, 2018

_ administradores», en Ius et Veritas núm. 53 (2016)

SÁnchez GonzÁlez, M. de la P., «Responsabilidad de la Administración por daños morales», en La responsabilidad patrimonial de la Administración pública, tomo I, Tomás Quintana López (dir.) y Anabelén Casares Marcos (coord.), 2ª ed., Tirant Lo Blanch, Valencia, 2013 


\title{
LA EXTENSIÓN AL DERECHO ADMINISTRATIVO SANCIONADOR DEL DERECHO HUMANO A SER INDEMNIZADO POR CONDENAS PENALES FIRMES ANULADAS
}

The extent to sanctioning administrative law of the human right to be compensated because of firm conviction reversed

\author{
Manuel Rodríguez Portugués \\ Universidad de Córdoba (España) \\ dp2ropom@uco.es
}

http://dx.doi.org/10.18543/ed-66(2)-2018pp191-217

\section{Copyright}

Estudios de Deusto es una revista de acceso abierto, lo que significa que es de libre acceso en su integridad. Se permite su lectura, la búsqueda, descarga, distribución y reutilización legal en cualquier tipo de soporte sólo para fines no comerciales, sin la previa autorización del editor o el autor, siempre que la obra original sea debidamente citada y cualquier cambio en el original esté claramente indicado 